\title{
Cathepsin L stimulates autophagy and inhibits apoptosis of ox-LDL-induced endothelial cells: Potential role in atherosclerosis
}

\author{
DANG-HENG WEI ${ }^{1,3,4}$, XIAO-YING JIA ${ }^{1,2}$, YANG-HUI LIU ${ }^{1}$, FENG-XIA GUO ${ }^{1}$, ZHI-HAN TANG ${ }^{1}$, \\ XIAO-HONG LI ${ }^{1}$, ZUO WANG ${ }^{1}$, LU-SHAN LIU ${ }^{1}$, GUI-XUE WANG ${ }^{3}$, \\ ZHI-SHENG JIAN $^{1}$ and CHANG-GENG RUAN ${ }^{4}$
}

\author{
${ }^{1}$ Institute of Cardiovascular Disease, Key Laboratory for Arteriosclerology of Hunan Province, \\ University of South China, Hengyang 421001; ${ }^{2}$ Department of Nursing, Xiangnan University, Chenzhou 423000; \\ ${ }^{3}$ Key Laboratory of Biorheological Science and Technology (Chongqing University), Ministry of Education, \\ Bioengineering College of Chongqing University, Chongqing 400044; ${ }^{4}$ First Affiliated Hospital of \\ Soochow University, Jiangsu Institute of Hematology, Key Laboratory of Thrombosis \\ and Hemostasis, Ministry of Health, Suzhou 215006, P.R. China
}

Received September 25, 2012; Accepted November 7, 2012

DOI: $10.3892 /$ ijmm.2012.1201

\begin{abstract}
The activation of endothelial cells by oxidized low-density lipoprotein (ox-LDL) with subsequent increases in endothelial permeability occurs in the early stage of atherosclerosis. Cathepsin L (CATL) is one of the cysteine proteases and has been implicated in advanced atherosclerotic lesions and plaque instability. This study aimed to explore the role of CATL in ox-LDL-induced early atherosclerotic events and to delineate the underlying mechanism. Results showed that ox-LDL upregulated CATL protein levels and activation in human umbilical vein endothelial cells (ECs) in a concentration-dependent manner and stimulated EC autophagy and apoptosis and increased EC monolayer permeability. Concomitantly, VE-cadherin expression was decreased. When ECs were pretreated with a CATL inhibitor, ox-LDL-induced autophagy was inhibited while apoptosis was further increased. In addition, the VE-cadherin protein level was increased, and the EC monolayer permeability was reduced. Taken together, the present study showed that the upregulated expression and activation of CATL induced by ox-LDL, increased EC autophagy and antagonized EC apoptosis, which partly neutralized the effect of increased EC monolayer permeability mediated by the downregulation of VE-cadherin. Thus, the proatherogenic effect of CATL was partly neutralized by inducing autophagy and inhibiting apoptosis in early stages of atherosclerosis.
\end{abstract}

Correspondence to: Dr Dang-Heng Wei, Institute of Cardiovascular Disease, Key Laboratory for Arteriosclerology of Hunan Province, University of South China, Hengyang 42001, P.R. China

E-mail: weizhonghua99@126.com

Key words: cathepsin L, oxidized low-density lipoprotein, endothelial cell, permeability, autophagy, apoptosis

\section{Introduction}

An elevated level of oxidized low-density lipoprotein (ox-LDL) is one of the major risk factors for atherosclerosis and plays a major role in vascular endothelial dysfunction. The vascular endothelium acts as a selective barrier, regulating the exchange of macromolecules between blood and the underlying tissues (1). The elevated permeability of the endothelium is the first event in the cascade of processes leading to atherosclerotic lesion formation, which leads to lipid infiltration and accumulation within the arterial wall. Three potential pathways regulate endothelial permeability: namely the transcellular pathway, by which blood components pass through the cell; the paracellular pathway, by which the components cross the endothelial barrier through intercellular cell-cell junctions; and the leaky junction pathway, by which components across the endothelium through the gap due to cells undergoing mitosis or apoptosis (2).

Cathepsins belong to the papain family of cysteine proteases, which degrade elastin and collagen. Cathepsin L (CATL) is one of the potent mammalian collagenases and elastases and was found to be upregulated in the arteries of apolipoprotein E-null mice fed a Western diet (3). Inhibition of CATL was able to reduce expression of the adhesion molecule $\alpha \mathrm{V} \beta 3$ integrin, disrupting secretion of the proangiogenic factors fibroblast growth factor (FGF) and vascular endothelial growth factor (VEGF) (4). Recently, Mahmoud et al (5) discovered that increased levels of CATL mRNA and protein induced by peroxisome proliferator-activated receptor $\gamma$ (PPAR $\gamma$ ) activation, stimulated apoptosis and inhibited autophagy in human monocyte-derived macrophages. These observations revealed that CATL contributes to atherosclerosis not simply its elastinolytic and collagenolytic activities.

In the present study, we investigated the role of CATL in ox-LDL-induced early atherosclerotic events and the potential mechanisms. As several studies have indicated that CATL activation exerts proatherogenic effects, we hypothesized 
that CATL activation decreases EC autophagy. Surprisingly, we found that a CATL inhibitor concentration-dependently decreased EC autophagy.

\section{Materials and methods}

Reagents. Dulbecco's modified Eagle's medium (DMEM), Trypsin, fluorescein isothiocyanate (FITC)-dextran and bovine serum albumin (BSA) were obtained from SigmaAldrich (St. Louis, MO, USA). ReverAid ${ }^{\mathrm{TM}}$ first-strand cDNA synthesis kit was purchased from Invitrogen Life Technologies (Carlsbad, CA, USA). CATL fluorogenic activity kit was purchased from Merck KGaA (Darmstadt, Germany). CATL inhibitor was purchased from Santa Cruz Biotechnology Inc. (Santa Cruz, CA, USA). Antibodies for CATL, beclin 1, LC3, caspase-3, Bcl-2, VE-cadherin, and HRP-labeled and alkaline phosphatase-labeled goat anti-rabbit IgG were obtained from Proteintech Biotechnology (Chicago, IL, USA). Ox-LDL was obtained from Zhongshan University (Guangzhou, China).

Cell culture. Human umbilical vein endothelial cells (ECs) were purchased from Central South University and cultured in DMEM supplemented with $10 \%$ fetal bovine serum (FBS; Invitrogen), $100 \mathrm{U} / \mathrm{ml}$ penicillin, and $100 \mu \mathrm{g} / \mathrm{ml}$ streptomycin. Cell cultures were maintained in a humidified incubator at $37^{\circ} \mathrm{C}$ in $5 \% \mathrm{CO}_{2}$ atmosphere. ECs were treated with ox-LDL or with a combination of pretreatment with a CATL inhibitor.

Cathepsin L activity assay. After treatment, cells were washed twice with ice-cold phosphate-buffered saline (PBS)

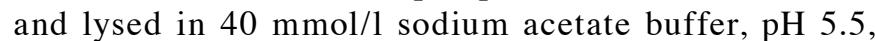
and $0.1 \%$ Triton $\mathrm{X}-100$. CATL activity was determined by the InnoZyme ${ }^{\mathrm{TM}}$ Cathepsin L fluorogenic activity kit. Following the manufacturer's protocol, Z-Phe-Arg-7-amido4-methylcoumarin (AMC) was used as a substrate. The reaction mixture was incubated at $37^{\circ} \mathrm{C}$ for $10 \mathrm{~min}$, and $\mathrm{AMC}$ fluorescence intensity was quantified with a fluorescence plate reader (excitation at $360 \mathrm{~nm}$ and emission at $460 \mathrm{~nm}$ ).

RNA extraction and analysis. Total cellular RNA was extracted using TRI reagent following the manufacturer's instructions. One microgram of the RNA sample was reversely transcribed to cDNA, and $2 \mu \mathrm{l}$ cDNA was added to the PCR amplification system. The primers were as follows: LC3 sense, 5'-GAGTTACCTCCCGCAGCCGCA-3' and antisense, 5'-TCCGCCGCTGCTTGAAAGGC-3'; beclin 1 sense, 5'-GGATGGATGTGGAGAAAGGCAAG-3' and antisense, 5'-TGAGGACACCCAAGCAAGACC-3'; caspase-3 sense, 5'-CAGGGCGCCATCGCCAAGTA-3' and antisense, 5'-TCA GCTCTGGCCTCCGGCTG-3'; Bcl-2 sense, 5'-GCATGGAG GGCAGTGACGCA-3' and antisense, 5'-TCGCAGGACACC CAGGACCC-3'; glyceraldehyde 3-phosphate dehydrogenase (GAPDH) sense, 5'-TCACCATCTTCCAGGAGCGAG-3' and antisense, 5'-TGTCCCTGTTGAAGTCAGAG-3'. The bands were visualized under UV light and the relative quantification of mRNA was assessed from the cycle threshold and normalized to GAPDH mRNA in the same samples.

Western blotting. ECs were treated with $0,25,50$ or $75 \mathrm{mg} / \mathrm{l}$ ox-LDL for $24 \mathrm{~h}$ or pretreated with $0,2,4$ or $8 \mathrm{mg} / \mathrm{l} \mathrm{CATL}$ inhibitors for $24 \mathrm{~h}$ and exposed to ox-LDL $(50 \mu \mathrm{g} / \mathrm{ml})$ for an additional $24 \mathrm{~h}$. Protein concentrations were measured using the BSA method as a standard. Equal amounts of total protein were resolved by SDS-PAGE, and the blots were probed with antibodies to CATL (1:500), beclin 1 (1:200), LC3 (1:200), caspase-3 (1:100), Bcl-2, VE-cadherin (1:100) (all were from Protech, USA), and appropriate secondary antibodies conjugated to alkaline phosphatase. Human $\beta$-actin served as the loading control. Blots were visualized with a chemiluminescence kit.

Quantification of apoptosis. Apoptotic cells were distinguished using propidium iodide (PI) staining. After treatment, cells were collected, washed with ice-cold PBS pH 7.4, centrifuged, and resuspended in $1 \mathrm{X}$ binding buffer. Cells were then incubated with fluorochrome for $15 \mathrm{~min}$ at $37^{\circ} \mathrm{C}$. Apoptotic rates were determined by flow cytometry (BD Biosciences, Franklin Lakes, NJ, USA) and analyzed using FlowJo software.

Permeability assay. Endothelial permeability was analyzed using the Costar Transwell system using an FITC-labeled dextran tracer. ECs were cultured to confluency on collagencoated polycarbonate membranes. In the final $1 \mathrm{~h}$ of the respective treatments, FITC-labeled dextran $(1 \mathrm{mg} / \mathrm{ml})$ was added to the upper chamber. Fluorescence in the lower compartment was measured after $2 \mathrm{~h}$ using a spectrofluorimeter (LS45; Perkin Elmer Life Sciences) with an excitation wavelength of $490 \mathrm{~nm}$ and emission wavelength of $520 \mathrm{~nm}$.

Statistical analysis. All experiments were repeated independently at least 3 times. Values were expressed as means $\pm \mathrm{SE}$. Student's unpaired t-test was used to establish significance between groups. $\mathrm{P}<0.05$ was considered to indicate a statistically significant difference.

\section{Results}

ox-LDL upregulates CATL protein expression and activation. After treatment of ECs with $0,25,50$ or $75 \mu \mathrm{g} / \mathrm{ml}$ ox-LDL for $24 \mathrm{~h}$, CATL protein levels (Fig. 1B) and activity (Fig. 1C) were increased in response to ox-LDL in a concentrationdependent manner. However, there was no significant change in the mRNA levels of CATL (Fig. 1A).

CATL inhibitor decreases ox-LDL-induced autophagy. After treatment with various concentrations of ox-LDL for $24 \mathrm{~h}$, the mRNA and protein expression of beclin 1 was increased in a concentration-dependent manner (Fig. 2A and $\mathrm{B}$ ). The ratio of LC3II/LC3I was also increased (Fig. 2B). Furthermore, monodansylcadaverine (MDC) staining revealed the accumulation of large MDC-stained vesicles (Fig. 2C).

Pretreatment of ECs with a CATL inhibitor decreased the protein levels of beclin 1 and the ratio of LC3II/LC3I (Fig. 3B). However, no obviously change in beclin 1 and LC3 mRNA expression was observed (Fig. 3A). The MDC-stained vesicles were attenuated in response to CATL inhibitor treatment (Fig. 3C).

CATL inhibitor increases ox-LDL-induced apoptosis. ECs treated with ox-LDL exhibited increased caspase-3 expression 
A
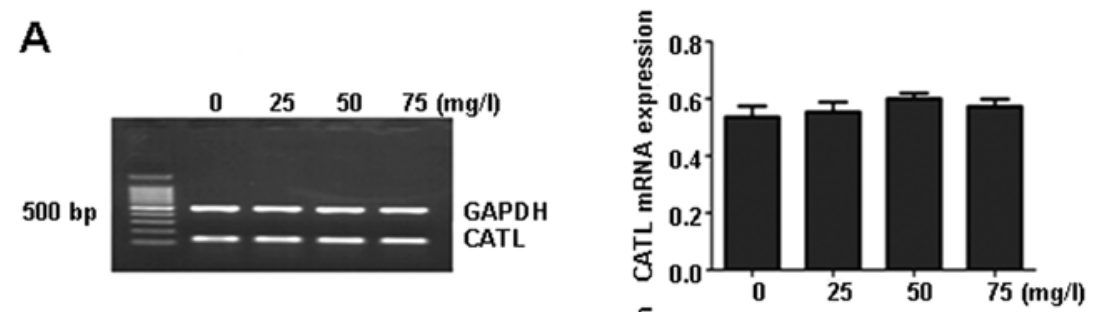

B
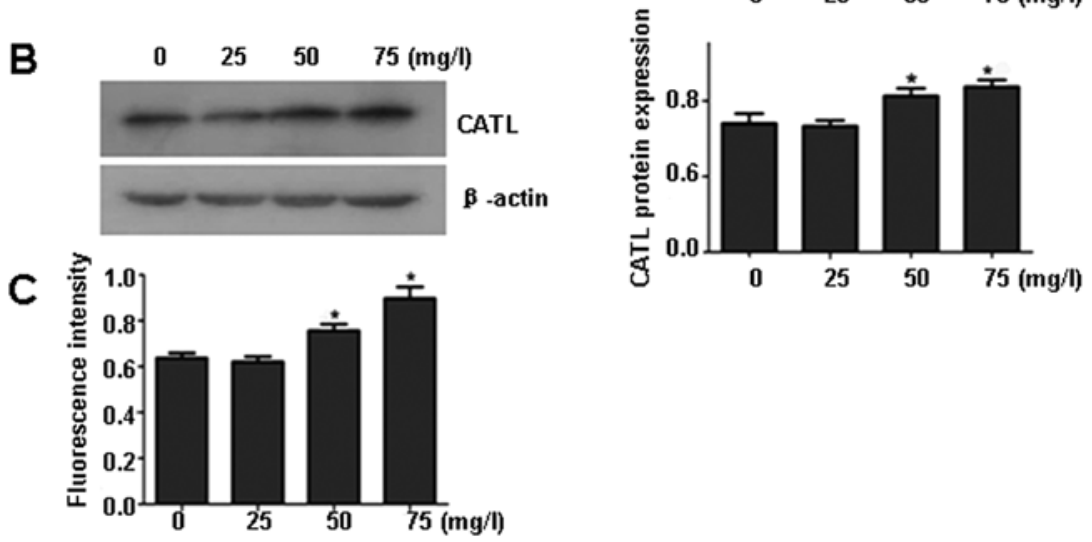

Figure 1. ox-LDL treatment induces CATL protein expression and activation. ECs were treated with different concentrations of ox-LDL for $24 \mathrm{~h}$. (A) Effects of ox-LDL on CATL mRNA. (B) Effects of ox-LDL on CATL protein expression. (C) Effects of ox-LDL on CATL activation. "P $<0.05$, compared to the $0 \mathrm{mg} / \mathrm{l}$ group, $\mathrm{n}=3$.

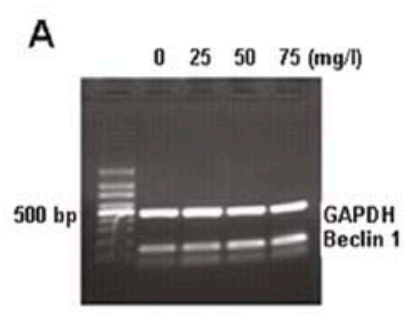

B

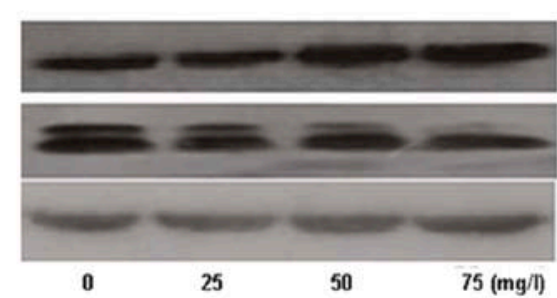

C

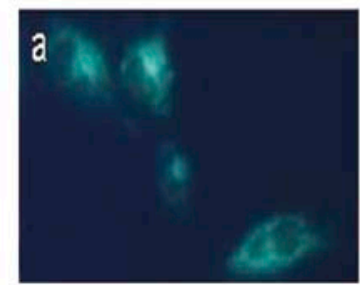

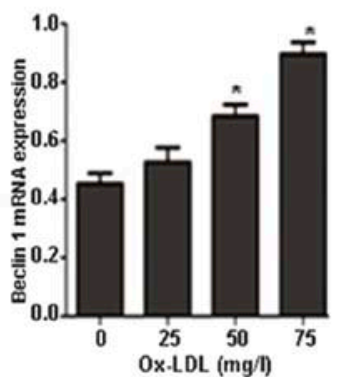
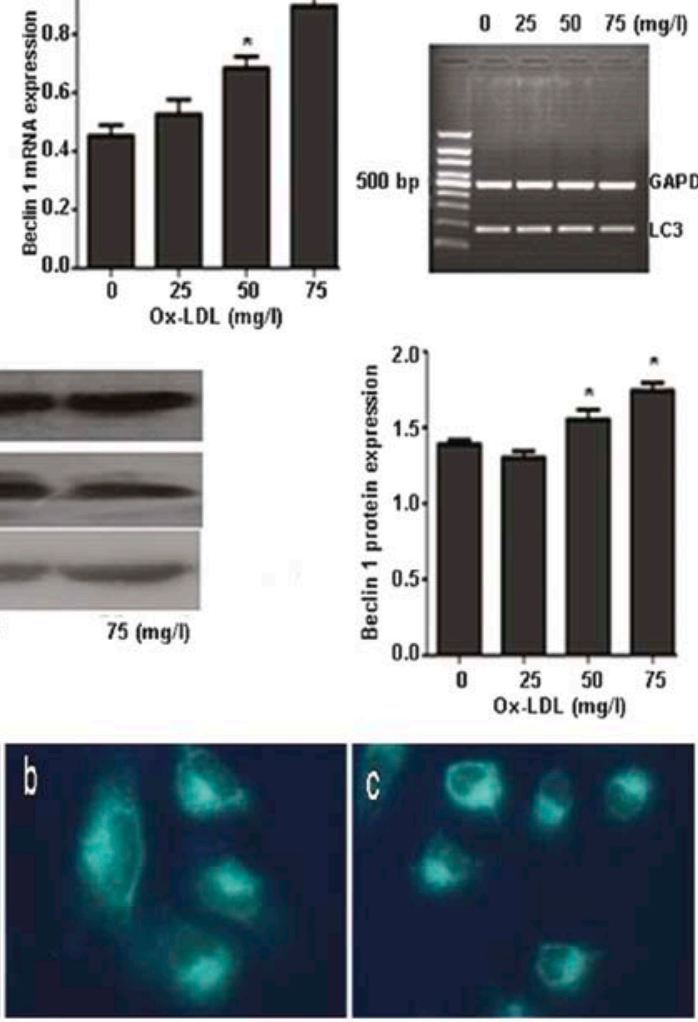
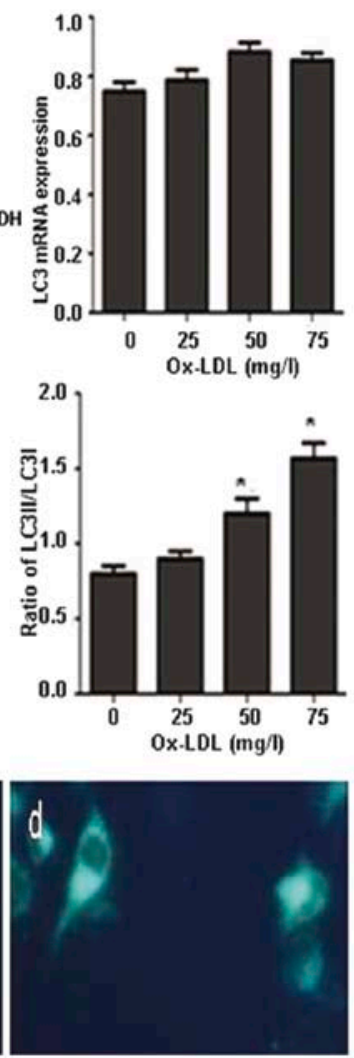

Figure 2. ox-LDL induces EC autophagy. (A) mRNA expression of beclin 1 and LC3 was analyzed by RT-PCR. (B) Protein expression of beclin 1 and LC3 was analyzed by western blotting. (C) MDC staining of ECs subjected to ox-LDL at a concentration of (a) $0 \mathrm{mg} / 1$, (b) $25 \mathrm{mg} / 1$, (c) $50 \mathrm{mg} / 1 \mathrm{and}$ (d) $75 \mathrm{mg} / 1$ (x40). ${ }^{*} \mathrm{P}<0.05$ compared with the $0 \mathrm{mg} / \mathrm{l}$ group, $\mathrm{n}=3$.

and a reduction in $\mathrm{Bcl}-2$ expression in a dose-dependent manner (Fig. 4A and B). Flow cytometry demonstrated that the percentage of apoptotic ECs was increased following ox-LDL treatment (Fig. 4C). 

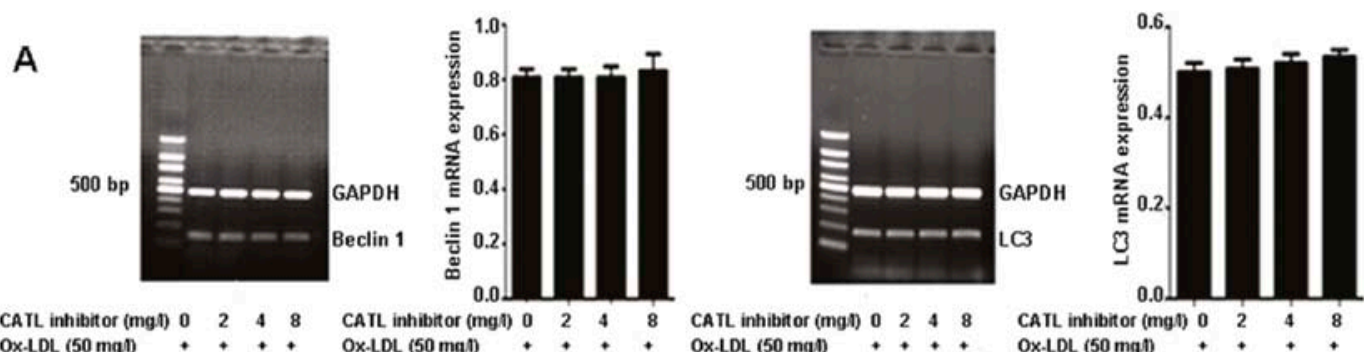

CAIL inhibitor (mgl) $0,2,4$
OX.LDL $(50$ mgl)

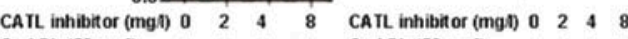

$\begin{array}{ccccc}\text { CATL inhibitor }(m g 1) & 0 & 2 & 4 & 8\end{array}$

B
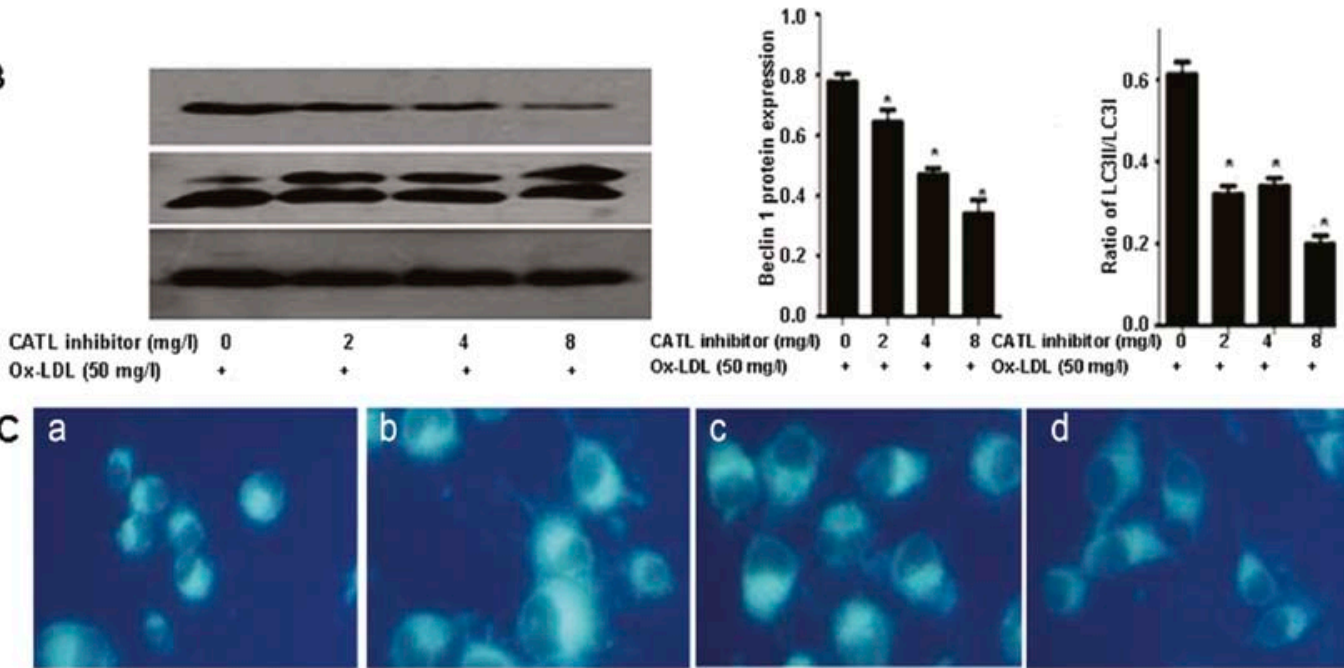

CAIL inhibitor (mgl) $0.254,8$ CAIL inhibitor
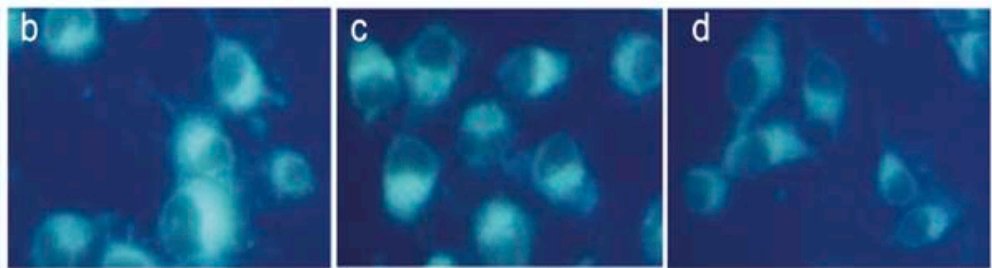

Figure 3. CATL inhibitor decreases ox-LDL-mediated EC autophagy. ECs were treated with various concentrations of a CATL inhibitor for $24 \mathrm{~h}$, followed by treatment with ox-LDL $(50 \mathrm{mg} / \mathrm{l})$ for an additional $24 \mathrm{~h}$. ox-LDL-induced EC autophagy was abrogated by the CATL inhibitor in a dose-dependent manner. (A) mRNA expression of beclin 1 and LC3 was analyzed by RT-PCR. (B) Protein expression of beclin 1 and LC3 was analyzed by western blotting. (C) MDC staining of ECs subjected to ox-LDL, (a) $0 \mathrm{mg} / \mathrm{l}$, (b) $25 \mathrm{mg} / \mathrm{l}$, (c) $50 \mathrm{mg} / \mathrm{l}$ and (d) $75 \mathrm{mg} / \mathrm{l}$ (x40). " $\mathrm{P}<0.05$ compared with the $0 \mathrm{mg} / \mathrm{l}$ group, $\mathrm{n}=3$.

A

B

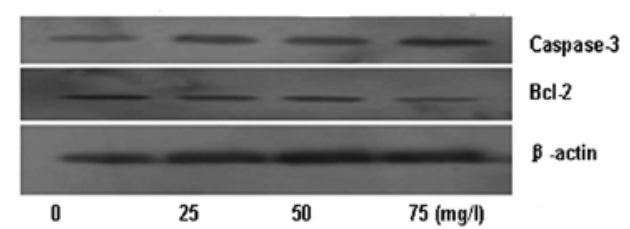

C

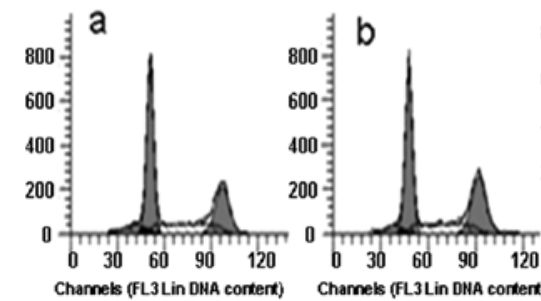

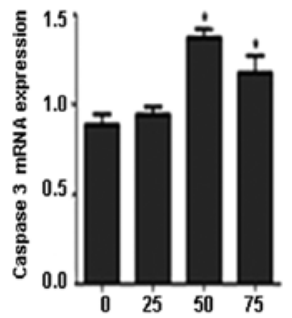

0x-LDL (mgl)
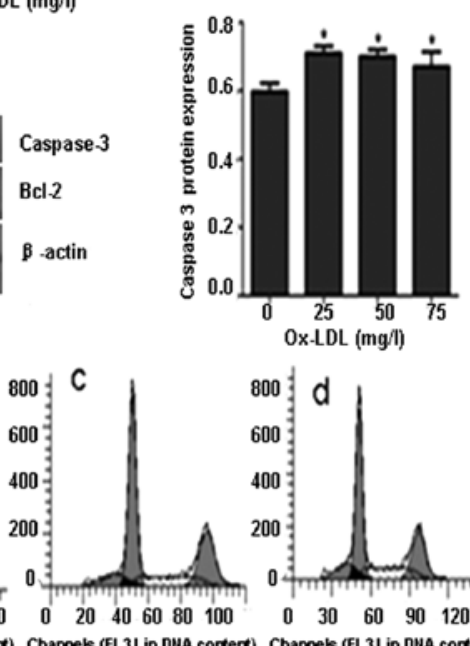

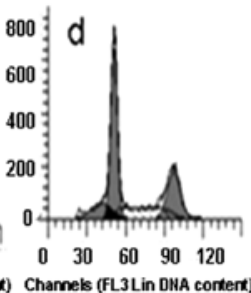

$0 \quad 25 \quad 50 \quad 75(\mathrm{mg} /)$
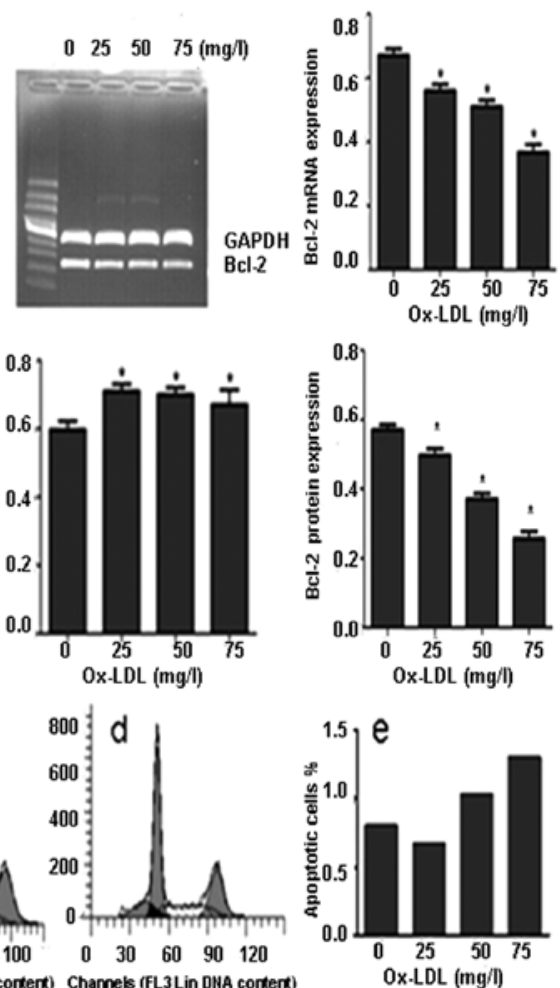

Figure 4. ox-LDL increases apoptosis of ECs. (A) mRNA expression of caspase-3 and Bcl-2 was analyzed by RT-PCR. (B) Protein expression of caspase-3 and Bcl-2 was analyzed by western blotting. (C) Apoptotic cells was measured using flow cytometry, (a) 0 mg/1, (b) $25 \mathrm{mg} / 1$, (c) $50 \mathrm{mg} / 1 \mathrm{and}$ (d) $75 \mathrm{mg} / 1$, (e) Apoptotic rate of ox-LDL treated ECs. ${ }^{*} \mathrm{P}<0.05$ compared with $0 \mathrm{mg} / \mathrm{l}$ group, $\mathrm{n}=3$. 


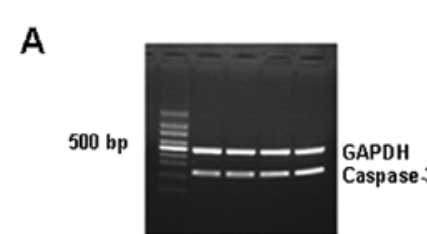

CAIL inhibitor (mgn) $0 \quad 2 \quad 4 \quad 8$ Ox-LDL (50 mgn) + + +

B

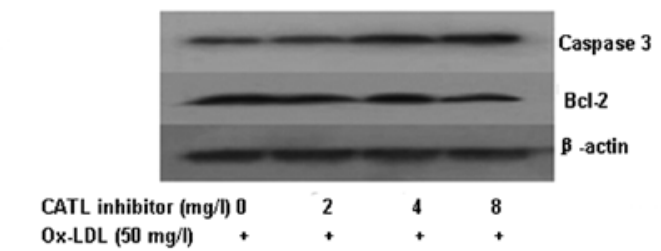

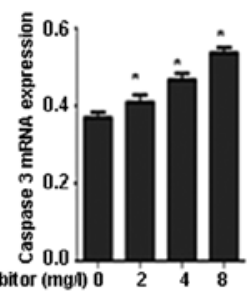

CATL inhibitor (mgl) 024 OX-LDL (50 mgn)

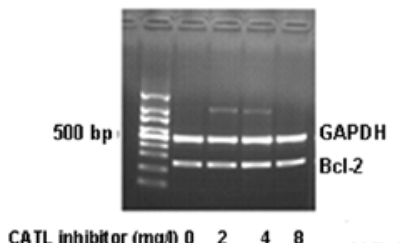

inhibit or $(m g l) 0 \quad 2 \quad 4 \quad 8$ OX-LDL (50 mgn) ++++

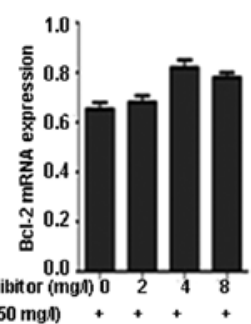

Ox-LDL (50 mgl) + + +

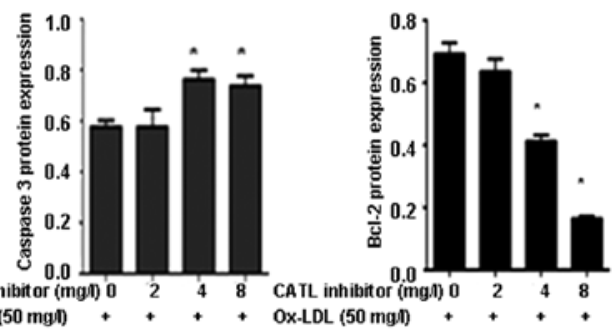

C
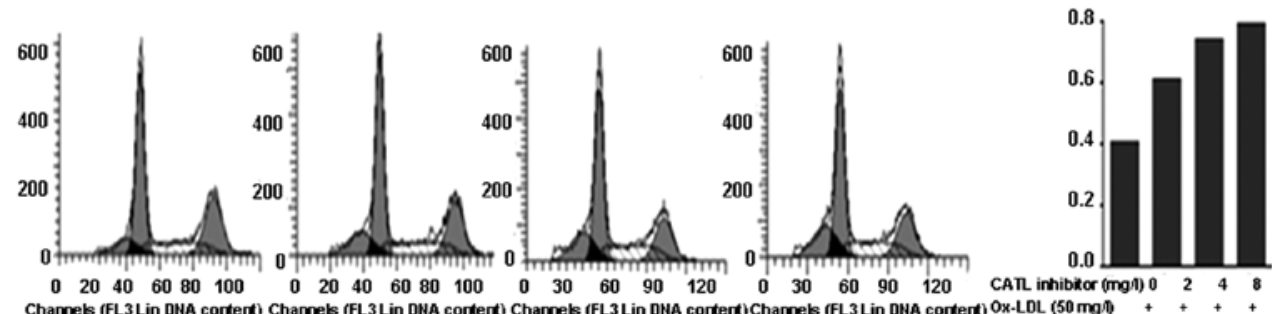

Figure 5. CATL inhibitor increases ox-LDL-mediated apoptosis of ECs. ECs were treated with various concentrations of a CATL inhibitor for $24 \mathrm{~h}$ and then exposed to ox-LDL (50 mg/l) for an additional $24 \mathrm{~h}$. CATL inhibitor increased ox-LDL-induced EC apoptosis in a dose-dependent manner. (A) mRNA expression of caspase-3 and Bcl-2 was analyzed by RT-PCR. (B) Protein expression of caspase-3 and Bcl-2 was analyzed by western blotting. (C) Apoptotic cells was measured using flow cytometry, (a) $0 \mathrm{mg} / \mathrm{l}$, (b) $2 \mathrm{mg} / 1$, (c) $4 \mathrm{mg} / 1$ and (d) $8 \mathrm{mg} / 1$, (e) Apoptotic rate of CATL inhibitor pretreated ECs. "P<0.05 compared with $0 \mathrm{mg} / \mathrm{l}$ group, $\mathrm{n}=3$.
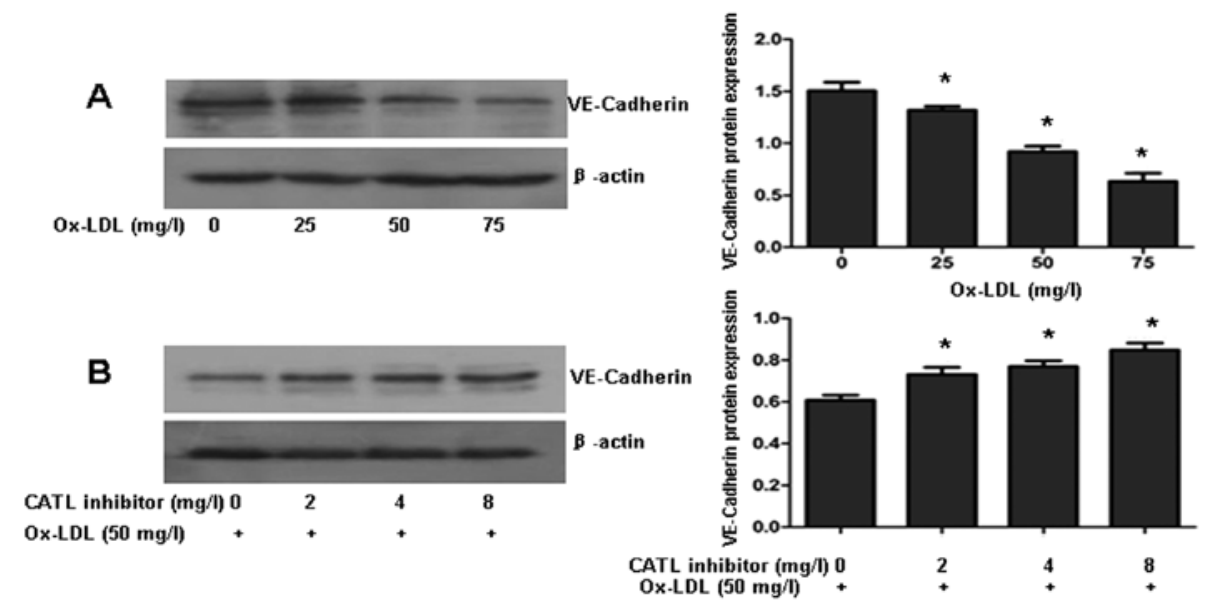

Figure 6. CATL inhibitor reverses the decrease of VE-cadherin induced by ox-LDL. (A) ox-LDL decreased the VE-cadherin protein content of ECs in a dosedependent manner. (B) CATL inhibitor pretreatment increased the VE-cadherin protein content of ECs treated by ox-LDL. ${ }^{*} \mathrm{P}<0.05, \mathrm{n}=3$.

After pretreatment with a CATL inhibitor, the mRNA and protein expression of caspase-3 was upregulated in response to the CATL inhibitor in a concentration-dependent manner (Fig. 5A and B). The expression of the Bcl-2 protein was further decreased (Fig. 5B). However, no significant change in mRNA levels of caspase-3 and Bcl-2 was observed (Fig. 5A). The apoptotic ratio of the ECs showed a concentration-dependent increase in response to the CATL inhibitor (Fig. 5C).
CATL inhibitor attenuates the ox- $L D L$-induced decrease in VE-cadherin. VE-cadherin is one of the most important molecules in the maintenance of endothelial integrity via its role in adherens junctions. Western blotting revealed that ox-LDL decreased VE-cadherin protein levels in a dosedependent manner (Fig. 6A). When ECs were preincubated with a CATL inhibitor for $24 \mathrm{~h}$, followed by exposure to ox-LDL $(50 \mathrm{mg} / \mathrm{l})$, downexpression of VE-cadherin protein was reversed by the CATL inhibitor (Fig. 6B). 

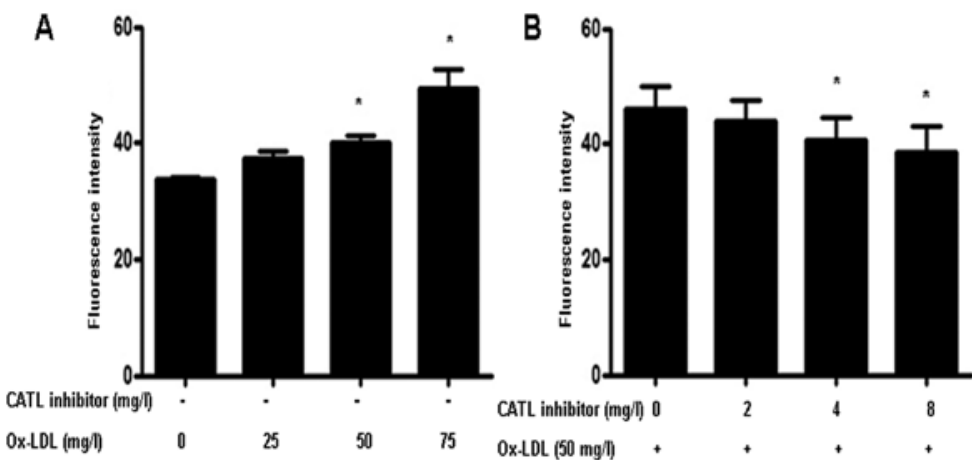

Figure 7. ox-LDL-induced cellular permeability is reduced by pretreatment with a CATL inhibitor. EC monolayer permeability was tested with a Transwell system and an FITC-labeled dextran tracer. (A) ECs were treated with 0, 25, 50 or $75 \mathrm{mg} / 1 \mathrm{ox}$-LDL for $24 \mathrm{~h}$. (B) ECs were pretreated with a CATL inhibitor for $24 \mathrm{~h}$, and then exposed to ox-LDL (50 mg/l) for $24 \mathrm{~h} .{ }^{*} \mathrm{P}<0.05, \mathrm{n}=3$.

Effect of the CATL inhibitor on endothelial monolayer permeability. Treatment of ox-LDL significantly increased endothelial cell permeability (Fig. 7A). However, when ECs were pretreated with a CATL inhibitor, the ox-LDL-induced increase in permeability was attenuated (Fig. 7B).

\section{Discussion}

CATL has previously been reported to be involved in the pregression of advanced atherosclerotic lesions. The present study investigated the effect of CATL on ox-LDL-induced early atherosclerotic events and its potential mechanisms. The results revealed that ox-LDL increased CATL protein expression and activation, inducing EC autophagy and apoptosis and increasing EC monolayer permeability. When ECs were pretreated with a CATL inhibitor, ox-LDL-induced autophagy was partly inhibited, while apoptosis was further increased. Concomitantly, the ox-LDL-induced decrease in VE-cadherin expression and increased EC monolayer permeability was attenuated by the CATL inhibitor.

It is important to note that the death of ECs by apoptosis is observed in the early stages of atherosclerosis. The permeability of cultured bovine aortic endothelial cell monolayers was found to be highly correlated with their rate of apoptosis and that inhibiting apoptosis lowers the permeability of monolayers to LDL (6). Several cathepsin family members have been implicated in apoptosis. In human cancer cells, cathepsin S siRNA induces autophagy and subsequent apoptosis (7). Cathepsin B induces mitochondrial release of cytochrome $c$ and activates caspase-3, signifying the onset of apoptotic cell death (8). In the present study, we found that pretreatment with a CATL inhibitor resulted in increased apoptotic cell death induced by ox-LDL, which means that the activation of CATL may inhibit the apoptosis of ECs.

In addition to apoptosis, the death of vascular cells by autophagy was also observed in this study. Autophagy is a catabolic pathway for the bulk turnover of long-lived proteins and organelles via lysosomal degradation. Basal autophagy is a survival mechanism safeguarding vascular cells against oxidative injury, metabolic stress and inflammation $(9,10)$; it is protective against EC injury and was observed in atherosclerotic plaques (11-15). Degradation of autophagolysosomal content is impaired in CATL(-/-) mice (16). In this study, we examined the mRNA and protein levels of beclin 1 (Bcl-2 interacting protein) and microtubule-associated protein 1 light chain 3 (LC3), which have previously been shown to promote autophagy. In ECs, the control cells exhibited few autophagic features. After treatment with ox-LDL, autophagy responses increased significantly. However, autophagy was significantly inhibited in the presence of the CATL inhibitor, indicating that upregulation of CATL may promote EC autophagy.

Previous observations indicate that autophagy and apoptosis are often induced by the same stimuli; they share similar effectors and regulators, and are subjected to complex crosstalk mechanisms. Recent studies have shown that beclin 1 and PI3K are substrates of caspases-3, -7 and -8 . Cleavage fragments lose the autophagy-inducing capacity, while enhancing apoptosis by promoting the release of proapoptotic factors from the mitochondria. It is worth noting that the C-terminal fragments, Beclin-1-C, localized predominantly at the mitochondria sensitized the cells to apoptosis (17). Thus, the possible mechanism of the CATL inhibitor-mediated increase in EC apoptosis may be explained, at least in part, by increased caspase-3 protein levels, which in turn create cleavaged beclin 1 consequently promoting EC apoptosis. Hence, we speculated that increased autophagic activity via CATL may overcome cell-death stimulation and decrease apoptotic cell death, which represents an adaptive process to benefit EC survival against ox-LDL damage.

The intercellular junctions of endothelial cells also have an important barrier function that regulates permeability. VE-cadherin is one of the main components of the endothelial cell-cell junction, which determines the strength of cell-cell adhesion and dictates monolayer properties (18). In our study, ox-LDL decreased the VE-cadherin protein levels in a dose-dependent manner. However, upon pretreatment with the CATL inhibitor, VE-cadherin protein contents were markedly increased. In particular, overexpression of CATL may contribute to the degradation of VE-cadherin induced by ox-LDL. Consistent with the importance of VE-cadherin to endothelial integrity, we found that pretreatment with the CATL inhibitor decreased the permeability induced by ox-LDL.

Taken collectively, we propose that the role of CATL in the alteration of ox-LDL-induced EC monolayer permeability is due to two factors. First, the inhibition of autophagy and 
induction of apoptosis by the CATL inhibitor suggest that the upregulation of the expression of CATL may provide the benefit of reducing endothelial cell monolayer permeability. Second, upregulation of the expression of CATL may involve the degradation of VE-cadherin, and this may be attributed to an increase in EC barrier permeability induced by ox-LDL. As a result, the proatherogenic effect of CATL may be neutralized by induction of EC autophagy.

\section{Acknowledgements}

The present research is supported by the National Natural Science Foundation of China (30800449), the Science and Technology Innovative Research Team in Higher Educational Institutions of Hunan Province and the Visiting Scholar Foundation of Key Laboratory of Biorheological Science and Technology (Chongqing University), the Ministry of Education.

\section{References}

1. Koch S and Nusrat A: Dynamic regulation of epithelial cell fate and barrier function by intercellular junctions. Ann NY Acad Sci 1165: 220-227, 2009.

2. Tarbell JM: Mass transport in arteries and the localization of atherosclerosis. Annu Rev Biomed Eng 5: 79-118, 2003.

3. Jormsjo S, Wuttge DM, Sirsjo A, Whatling C, Hamsten A, Stemme $S$ and Eriksson P: Differential expression of cysteine and aspartic proteases during progression of atherosclerosis in apolipoprotein E-deficient mice. Am J Pathol 161: 939-945, 2002.

4. Rebbaa A, Chu F, Sudha T, Gallati C, Dier U, Dyskin E, Yalcin M, Bianchini C, Shaker O and Mousa SA: The antiangiogenic activity of NSITC, a specific cathepsin L inhibitor. Anticancer Res 29: 4473-4481, 2009.

5. Mahmood DF, Jguirim-Souissi I, Khadija el-H, Blondeau N, Diderot V, Amrani S, Slimane MN, Syrovets T, Simmet T and Rouis M: Peroxisome proliferator-activated receptor gamma induces apoptosis and inhibits autophagy of human monocytederived macrophages via induction of cathepsin L: potential role in atherosclerosis. J Biol Chem 286: 28858-28866, 2011.

6. Cancel LM and Tarbell JM: The role of apoptosis in LDL transport through cultured endothelial cell monolayers. Atherosclerosis 208: 335-341, 2010.
7. Chen KL, Chang WS, Cheung $\mathrm{CH}$, Lin $\mathrm{CC}$, Huang CC, Yang YN, Kuo CP, Kuo CC, Chang YH, Liu KJ, Wu CM and Chang JY: Targeting cathepsin $\mathrm{S}$ induces tumor cell autophagy via the EGFR-ERK signaling pathway. Cancer Lett 317: 89-98, 2012.

8. Bhoopathi P, Chetty C, Gujrati M, Dinh DH, Rao JS and Lakka S: Cathepsin B facilitates autophagy-mediated apoptosis in SPARC overexpressed primitive neuroectodermal tumor cells. Cell Death Differ 17: 1529-1539, 2010.

9. Ouimet M, Franklin V, Mak E, Liao X, Tabas I and Marcel YL: Autophagy regulates cholesterol efflux from macrophage foam cells via lysosomal acid lipase. Cell Metab 13: 655-667, 2011.

10. Zhang YL, Cao YJ, Zhang X, Liu HH, Tong T, Xiao GD, Yang YP and Liu CF: The autophagy-lysosome pathway: a novel mechanism involved in the processing of oxidized LDL in human vascular endothelial cells. Biochem Biophys Res Commun 394: 377-382, 2010.

11. Liao X, Sluimer JC, Wang Y, Subramanian M, Brown K, Pattison JS, Robbins J, Martinez J and Tabas I: Macrophage autophagy plays a protective role in advanced atherosclerosis. Cell Metab 15: 545-553, 2012.

12. Mei S, Gu H, Ward A, Yang X, Guo H, He K, Liu Z and Cao W: p38 mitogen-activated protein kinase (MAPK) promotes cholesterol ester accumulation in macrophages through inhibition of macroautophagy. J Biol Chem 287: 11761-11768, 2012.

13. Zhaorigetu S, Yang Z, Toma I, McCaffrey TA and Hu CA: Apolipoprotein L6, induced in atherosclerotic lesions, promotes apoptosis and blocks Beclin 1-dependent autophagy in atherosclerotic cells. J Biol Chem 286: 27389-27398, 2011.

14. Xie Y, You SJ, Zhang YL, Han Q, Cao YJ, Xu XS, Yang YP, Li J and Liu CF: Protective role of autophagy in AGE-induced early injury of human vascular endothelial cells. Mol Med Rep 4: 459-464, 2011

15. Martinet W and De Meyer GR: Autophagy in atherosclerosis. Curr Atheroscler Rep 10: 216-223, 2008.

16. Dennemärker J, Lohmüller T, Müller S, Aguilar SV, Tobin DJ, Peters $\mathrm{C}$ and Reinheckel T: Impaired turnover of autophagolysosomes in cathepsin L deficiency. Biol Chem 391: 913-922, 2010.

17. Wirawan E, Vande Walle L, Kersse K, Cornelis S, Claerhout S, Vanoverberghe I, Roelandt R, De Rycke R, Verspurten J, Declercq W, Agostinis P, Vanden Berghe T, Lippens S and Vandenabeele P: Caspase-mediated cleavage of Beclin-1 inactivates Beclin-1-induced autophagy and enhances apoptosis by promoting the release of proapoptotic factors from mitochondria. Cell Death Dis 1: e18, 2010.

18. Sakamoto N, Segawa K, Kanzaki M, Ohashi T and Sato M: Role of p120-catenin in the morphological changes of endothelial cells exposed to fluid shear stress. Biochem Biophys Res Commun 398: 426-432, 2010 